\title{
A Comparative Study:Is Misoprostol as Effective as Oxytocin in Active Management of Third Stage of Labor?
}

\section{Prem Raj Pangeni ${ }^{1}$, Padma Raj Dhungana ${ }^{2}$, Rajesh Adhikari ${ }^{3}$}

${ }^{1}$ Department of Obstetrics and Gynecology,Pokhara Academy of Health Sciences, Western Regional Hospital

\section{Correspondence}

Dr. Prem Raj Pageni

Department of Obstetrics and Gynecology

Pokhara Academy of Health Sciences, Western

Regional Hospital,Pokhara, Nepal

Email: Prpageni@gmail.com

Article received: Oct 142019

Article accepted: Aug 12020

\section{ABSTRACT}

Background: The third stage of labor is that period from birth of the infant until the delivery of the placenta. Active management of the third stage of labor plays an important role in reducing maternal morbidity and mortality. Oxytocin is an effective drug in preventing postpartum hemorrhage (PPH) however; it requires a controlled environment and intramuscular administration.Misoprostol is an orally active uterotonic agent,stable at room temperature. The purpose of this study was to compare the efficacy of misoprostol with oxytocin in active management of third stage of labor.

Materials and Methods: This was a hospital based study carried out in Paropakar Maternity and Women Hospital, Kathmandu, Nepal during six months period from February 2012 to July 2012. One hundred patients fulfilling inclusion criteria were recruited to receive either 10 unit of IM oxytocin or $600 \mathrm{mcg}$ of oral misoprostol for the management of the third stage of labor.

Results: The mean blood loss in misoprostol and oxytocin group was $209 \pm 76.7 \mathrm{ml}$ and $197 \pm 68.8$ $\mathrm{ml}$ respectively with $\mathrm{p}$ value- 0.41 which was insignificant. Similarly mean hemoglobin change was also not significant. The additional uterotonics needed in misoprostol was higher ( 9 cases) than that in oxytocin ( 5 cases) but it was also not significant. Shivering and fever were significantly high among misoprostol group than in oxytocin group.

Conclusion: Efficacy of oxytocin and misoprostol is equal in active management of third stage of labor.

Keywords: misoprostol, oxytocin, postpartum hemorrhage. 


\section{INTRODUCTION}

The precise definition of normal labor is the spontaneous onset of regular painful uterine contractions associated with progressive effacement and dilation of the cervix resulting in delivery offet us, placenta and its membrane. ${ }^{1}$ Active management of the third stage of labor can directly influence important maternal outcomes, such as blood loss, the need for the manual removal of placenta and the incidence of $\mathrm{PPH} .{ }^{2}$ The active management of the third stage of labor comprises using uterotonics (oxytocic), clamping and cutting the umbilical cord and delivery of placenta by controlled cord traction (CCT) method. This approach reduces the risk of $\mathrm{PPH}$, postpartum anemia, blood transfusion requires prolong third stage of labor and use of therapeutic drugs for $\mathrm{PPH} .^{3}$

The most common complication of the third stage of labor is primary PPH. PPH is defined as the loss of more than $500 \mathrm{ml}$ of blood from the genital tract after delivery or any loss of less than $500 \mathrm{ml}$, that deranges hemodynamic stability of mother.Most cases of PPH, greater than $99 \%$, are early postpartum hemorrhage. ${ }^{4}$ Immediate PPH is most commonly caused by uterine atony. This can be counteracted by effective use of uterotonics or oxytocics. ${ }^{5}$

Misoprostol is inexpensive and can be administered sublingually, orally, rectally and vaginally. It is stable at room temperature, no need of refrigeration for its storage.Misoprostol is a proven uterotonic agent with bioavailabity following oral administration.

Hence in low resource setting like in rural places of Nepal, misoprostol can a good option for the effective management of the third stage of labor. ${ }^{6}$ This study was conducted to compare the efficacy of oral misoprostol with oxytocin in the active management of the third stage of labor.

\section{MATERIALS AND METHODS}

It was a hospital based comparative study.The study was conducted at Paropakar Maternity and Women Hospital, Thapathali, Kathmandu,Nepal after getting ethical clearance from Institutional Review Board, National Academy of Medical Sciences. The duration of study was six months from April 2012 till Sept 2012. One group was allocated for intramuscular oxytocin $10 \mathrm{IU}$, the other for 600microgram of misoprostol orally, both in third stage of labor. The inclusion criteria include singleton pregnancy. The exclusion criteria includes previous caesarian section, patient undergoing caesarian section, anaemia with hemoglobin less than $8 \mathrm{gm} / \mathrm{dl}$, induction with oxytocin and instrumental delivery. The amount of blood loss and side effects were recorded in both the groups. All these enrolled cases were followed throughout the hospital stay till discharge.

\section{RESULTS}

Table1.Comparison between two groups on the basis of total blood loss

\begin{tabular}{|l|l|l|l|l|l|}
\hline \multirow{2}{*}{$\begin{array}{c}\text { Total blood } \\
\text { loss }\end{array}$} & \multicolumn{2}{c|}{$\begin{array}{c}\text { Oxytocin } \\
\text { Group }\end{array}$} & \multicolumn{2}{c|}{$\begin{array}{c}\text { Misoprostol } \\
\text { Group }\end{array}$} & \multirow{2}{*}{$\begin{array}{l}\text { P- } \\
\text { value }\end{array}$} \\
\cline { 2 - 6 } & $\mathrm{N}$ & $\%$ & $\mathrm{~N}$ & $\%$ & \\
\hline $0-100 \mathrm{ml}$ & 0 & 0 & 0 & 0 & 0 \\
\hline $101-200 \mathrm{ml}$ & 30 & 60 & 27 & 44 & 0.36 \\
\hline $201-300 \mathrm{ml}$ & 18 & 36 & 18 & 36 & 1.00 \\
\hline $301-400 \mathrm{ml}$ & 1 & 2 & 4 & 16 & 0.04 \\
\hline$\geq 500 \mathrm{ml}$ & 1 & 2 & 1 & 2 & 1.00 \\
\hline $\begin{array}{l}\text { Mean } \\
\text { blood loss, } \\
\text { mean } \pm \mathrm{SD}\end{array}$ & $197.0 \pm 68.8$ & $209.0 \pm 76.7$ & 0.41 \\
\hline
\end{tabular}

The above table shows the different ranges of blood loss in the two groups. Most of the deliveries had blood loss in the range of 101-200 ml, only one case in each group had PPH. The mean amount of blood loss in the third stage of labor in the misoprostol group ( $209 \mathrm{ml}$ ) was higher than that of Oxytocin group $(197 \mathrm{ml})$, which is not statistically significant (P value 0.41$)$

Table 2. Change in $\mathrm{Hb}$ concentration in two groups

\begin{tabular}{|c|c|c|c|c|c|c|c|c|}
\hline \multicolumn{3}{|c|}{ Oxytocin Group } & \multicolumn{3}{|c|}{ Misoprostol Group } & \multicolumn{3}{|c|}{$\begin{array}{c}\text { Mean change in } \\
\mathrm{Hb}\end{array}$} \\
\hline 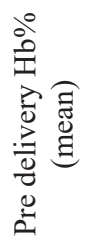 & 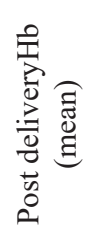 & $\frac{\stackrel{0}{ٍ}}{\frac{\pi}{J}}$ & 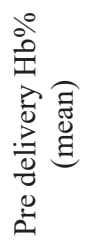 & 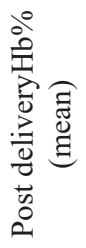 & 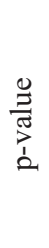 & 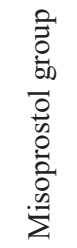 & 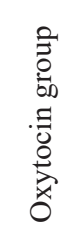 & 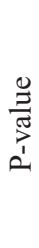 \\
\hline $10.8 \pm 0.6$ & $10.6 \pm 0.6$ & 0.06 & $11.02 \pm 0.8$ & $10.74 \pm 0.8$ & 0.1 & $0.23 \pm 0.2$ & $0.28 \pm 0.2$ & 0.24 \\
\hline
\end{tabular}


Original Article

The above table shows change in hemoglobin in two groups.Predelivery and post delivery hemoglobin was taken.The mean changes in hemoglobin in oxytocin group and misoprostol group were $0.28 \pm$ 0.2 and $0.23 \pm 0.2$ respectively, $\mathrm{p}$ value being 0.24 , which is statistically not significant.

Table3. Side effects of given drugs

\begin{tabular}{|l|l|l|l|l|l|}
\hline \multirow{2}{*}{\begin{tabular}{c}
\multirow{2}{*}{$\begin{array}{c}\text { Side } \\
\text { effects }\end{array}$} \\
\cline { 2 - 6 }
\end{tabular}} & \multicolumn{2}{c|}{$\begin{array}{c}\text { Oxytocin } \\
\text { Group }\end{array}$} & \multicolumn{2}{c|}{$\begin{array}{c}\text { Misoprostol } \\
\text { Group }\end{array}$} & \multirow{2}{*}{ p-value } \\
\hline Nausea & 5 & 10 & 9 & 18 & 0.38 \\
\hline Vomiting & 4 & 8 & 3 & 6 & 1.00 \\
\hline Shivering & 5 & 10 & 24 & 48 & 0.00 \\
\hline Fever & 1 & 2 & 14 & 28 & 0.00 \\
\hline Diarrhoea & 1 & 2 & 5 & 10 & 0.56 \\
\hline
\end{tabular}

The above table shows shivering and fever were significantly higher in misoprostol group (48\% versus $10 \%$ for shivering, $28 \%$ versus $2 \%$ for fever). Nausea was found in $10 \%$ in oxytocin group and in $18 \%$ in misoprostol group which is not significant. Vomiting was found in 4 patients in oxytocin group and in 3 patients in misoprostol group.Diarrhoea was found in higher number of patient in misoprostol group.

Table 4. Need for further management in two groups

\begin{tabular}{|l|l|l|l|l|l|}
\hline \multirow{2}{*}{$\begin{array}{c}\text { Method of } \\
\text { management }\end{array}$} & \multicolumn{2}{|c|}{$\begin{array}{c}\text { Oxytocin } \\
\text { Group }\end{array}$} & \multicolumn{2}{|c|}{$\begin{array}{c}\text { Misoprostol } \\
\text { Group }\end{array}$} & p-value \\
\cline { 2 - 6 } & $\mathrm{N}$ & $\%$ & $\mathrm{~N}$ & $\%$ & \\
\hline $\begin{array}{l}\text { Further } \\
\text { oxytocics }\end{array}$ & 5 & 10 & 9 & 18 & 0.38 \\
\hline $\begin{array}{l}\text { Blood } \\
\text { transfusion }\end{array}$ & 0 & 0 & 1 & 2 & 1.00 \\
\hline $\begin{array}{l}\text { Manual } \\
\text { removal of } \\
\text { placenta }\end{array}$ & 1 & 2 & 2 & 4 & 1.00 \\
\hline
\end{tabular}

Above mentioned table shows needs of further management for increased amount of bleeding.

\section{DISCUSSION}

$\mathrm{PPH}$ is the major cause of maternal morbidity and mortality globally. It is more prevalent in the developing countries. ${ }^{6}$ More than half of the maternal death occurs within $24 \mathrm{hrs}$ of the delivery, mostly from the atonic uterus. Recently various methods have been employed to encounter such
A Comparative Study:Is misoprostol as effective as oxytocin. Pangeni R P. et. al. primary PPH to decrease maternal morbidity and mortality. ${ }^{5}$ One of the effective measures to prevent $\mathrm{PPH}$ is the active management of the third stage of labor.

Several uterotonic agents are being used for the prevention of $\mathrm{PPH}$ in active management of the third stage of labor. The purpose of our study was to compare the efficacy and the safety of $600 \mathrm{mcg}$ misoprostol orally with standard IM oxytocin (10 i.u intramuscular oxytocin) in the active management of the third stage of labor.

In a study conducted by Savita Rani et al. in RohtakHarayana, India compared the use of $400 \mathrm{mcg}$ of sublingual misoprostol for third stage of labor management with 10 unit of IM oxytocin in active management of third stage of labor, the mean blood loss was $260.35 \pm 97.45 \mathrm{ml}$ in misoprostol group and $260.20 \pm 103.68 \mathrm{ml}$ in oxytocin group. ${ }^{7}$ This amount of blood loss is slightly higher than in our study although the difference was statistically not significant.N Sultana found blood loss of $325.4 \mathrm{ml}$ in misoprostol group and $375 \mathrm{ml}$ blood loss in oxytocin group which is higher than in our study but the differencewas not significantas well. ${ }^{8}$

A study done by V. O. Oboro etal. found blood loss of $341 \mathrm{ml}$ in misoprostol group $(600 \mathrm{mcg}$ orally) and $339 \mathrm{ml}$ in the oxytocin group. ${ }^{9}$ They found that in misoprostol group the additional uterotonics needed was in 31 cases out of $247(12.6 \%)$ but in oxytocin group only 27 patients out of 249 (10.8\%) needed additional oxytocics although it was not statistically significant. ${ }^{9}$

In contrast to above studies, a study by Steven $\mathrm{M}$ Parsons et al. found out that there was an increase in use of additional uterotonics in oxytocin group than that in misoprostol group. ${ }^{10}$ Sixteen patients out of $225(7.1 \%)$ in misoprostol group needed additional oxytocics whereas in oxytocin group 21 patients out of $225(9.3 \%)$ needed additional uterotonics. But the $\mathrm{P}$ value was not statistically significant.

Afolabi E Oet al. found that 4 patients out of 100 in oxytocin group needed oxytocic additionally whereas in misoprostol group only 3 patients out of 100 needed additional oxytocics though the $P$ value is 0.70 which was not significant.$^{11}$

Our study measured hemoglobin change before delivery in labor and 12 hourspost delivery. In this study the mean decrease in hemo globin 
Original Article

concentration was $0.23( \pm 0.2) \mathrm{gm} / \mathrm{dl}$ for misoprostol group and $0.28( \pm 0.2) \mathrm{gm} / \mathrm{dl}$ for the oxytocin group; a difference that was not significant ( mean change in $\mathrm{p}$ value $=0.24$ ). In other study bySteven M Parsons etal found decrease in hemoglobin concentration by $1.07( \pm 1.14) \mathrm{gm} / \mathrm{dl}$ for the misoprostol group and $1.00( \pm 1.04) \mathrm{gm} / \mathrm{dl}$ in oxytocin group, a difference that was not significant (relative difference $7 \% ; 95 \% \mathrm{CI}$ (Confidence Interval)$13,27 \%, \mathrm{P}=0.54){ }^{10}$

V O Oboro etal. found a difference in hemoglobin concentration in misoprostol group as $0.71 \mathrm{gm} / \mathrm{dl}$ and in oxytocin group as $0.68 \mathrm{gm} / \mathrm{dl}(\mathrm{P}$ value 0.699$)$ which was not signicifant. ${ }^{9}$

There were no serious adverse events in our study. All the adverse effects were mild and they subsided spontaneously. None of them required any intervention and were managed with close monitoring. Prostaglandin related side effects especially shivering, pyrexia, nausea, vomiting and diarrhoea were more frequent and consistent with the trials done by others. In our study 24(48\%) patients developed shivering in misoprostol group but only $5(10 \%)$ patients developed shivering in oxytocin group. Similarly, fever was seen in $14(28 \%)$ patients in misoprostol group whereas only $1(2 \%)$ patient developed fever in oxytocin group. So, shivering and fever were seen in large number of patients showing statistically significance adverse effects in misoprostol group than in oxytocin group. Nine patients in misoprostol group developed nausea which was seen in only 5 patients of oxytocin group. Diarrhea was seen in 5 patients in misoprostol group while only one patient developed diarrhea in oxytocin group. Vomiting was seen in $8 \%$ of the oxytocin groupbut in misoprostol group it was only $6 \%$ which is statistically not significant. These side effects were minor and self-limiting. They caused discomfort, shivering and needed extra blanket but none of them needed extra medication for these symptoms and were reassured.

A study done by $\mathrm{N}$ Sultana etal. found that shivering was developed by 13 patients out of 210 in misoprostol group (6.19\%) whereas in oxytocin group only 2 patients $(1.05 \%)$ developed shivering, showing statistically significantP Value $(\mathrm{P}$ value $<$ 0.1 ). But the incidence of diarrhea and fever was found in $1.9 \%$ in misoprostol group (4 patients) and
Medical Journal of Pokhara Academy of Health Sciences Vol. 3 Issue 2 only in 2 patients in oxytocin group $(1.05 \%)$, where the P Value was not significant (Pvalue $=0.2) .{ }^{8}$

From the above findings, it has been observed that in all parameters except shivering, there were no significant differences in side effects between misoprostol and oxytocin group in our study.

\section{CONCLUSION}

In our study, use of $600 \mathrm{mcg}$ oral misoprostol was as effective as oxytocin in the AMTSL for the prevention of PPH. The side effects were higher in Misoprostol group but they were minor, selflimiting, did not require any intervention.Hence, it can be concluded that Misoprostol is as equally effective as Oxytocin in active management of third stage of labor.

\section{RECOMMENDATION}

This study has concluded that oral Misoprostol is as effective as Oxytocin in AMTSL, so it advocates that Misoprostol could be the alternative to oxytocin in health facility, poor set up or in home deliveries as well to reduce maternal mortality and morbidity by reducing PPH.However the sample size in this study is small, other study in large sample size is recommended.

\section{REFERENCES}

1. FraserDI, Mukhopadhya S. The management of first stage of labor; Arulkumaran S. etal, The management of labor: second edition,2005:26-50. Orient Longman.

2. World Health Organization.Take every mother and child count.Geneva:the World Health Organization,2005:62-3.

3. Prendiville W J,ElbourneD,ChalmersI.The effects of routine oxytocic administration in the management of the third stage of labor: an overview of the evidence from controlled trials.Br J Obstet Gynaecol1988;95:3-16.

4. .MaameYaazA B Yiadom, Dyne .F,CarusiA,SayahA.J,ZwangerM,Halamka J.D. Postpartum hemorrhage in Emergency Medicine.April 20, 2010

5. Nordstrom L,Fogelstam K, FridmanG,LarssonA,RydhstroemH.Routine 
oxytocin in the third stage of labor: a placebo controlled randomized trial. $\mathrm{Br} \mathrm{J}$ ObstetGynecol 1997;104:781-786.

6. Subedi B K. et. al. Nepal Maternal mortality and morbidity in 2008-2009

7. SinghaiS.R,GuptaN,Kzunika, Smiti Nanda, Sublingual Misoprostol Verses Intramuscular Oxytocin in the Active Management of the Third Stage of Labor, South Asia Federation of Obstetrics and Gynecology; September-December 2010; 2(3):199-202.

8. Sultana N, Khatun M; Misoprostol versus Oxytocin in the Active Management of the third Stage of Labor; Journal of Bangladesh College of physicans and Surgeons, Vol 25, No 2, May 2007;73-76.

9. OboroV.O.andTabzoweiT.O. ARandomized Controlled Trial of Misoprostol Versus Oxytocin in the Active Management of the Third Stage of Labor, Journal of obstetrics and Gynecology (2003z), vol 23, No.1, 1316

10. Parson S.M, Walley R.L, Joan M.G crane, Matthews K, Hutchens D. Rectal Misoprostol Versus Oxytocin in the Management of the Third Stage of Labor, J ObstGynaecol Can 20z07; 29(9): 711-718.

11. Afolabzi E O, Kuti U, Orji Reo, Ogunniyi SO. Oral Misoprostol Versus Intramuscular Oxytocin in the active Management of the Third Stage of Labor; Singapore med J 2010; 51(3):207-11 